\title{
Channel capacity in the magnitude estimation of weight
}

\author{
ANTE FULGOSI \\ Odsjek za psihologiju, Filozofski fakultet, Zagreb, Yugoslavia \\ and \\ PETAR BEZINOVIĆ, IVO MIMICA, and VLADIMIR TAKŠIĆ \\ Odsjek za psihologiju, Filozofski fakultet, Zadar, Yugoslavia
}

\begin{abstract}
Information transmission was compared for magnitude estimation and absolute judgment of weight. Three groups of 5 subjects made magnitude estimations with a standard to which they could always refer, magnitude estimations with a standard presented once at the beginning of each judgment session, or absolute judgments of weight. Ten weights (22-292 g), with an informational value of 3.32 bits, composed the stimulus set. Informational analyses showed that information transmitted by magnitude estimations was between 1.60 and 2.26 bits, and that this did not differ from the value of 1.91 for absolute judgments; thus, channel capacity limits both kinds of judgments in spite of the large apparent task differences. Subjects used between 3 and 5 intensity categories in estimating weights; thus, this number does not depend on response uncertainty, the ranges and ratios of subjective scales, or the numbers subjects use in magnitude estimations. It is concluded that one-to-one mappings between the physical and psychological dimensions of weight cannot be carried out. Nevertheless, the finding that subjective estimates of weight contain intensity information about stimuli supports the possibility of a new objective psychophysics.
\end{abstract}

Informational analyses of psychophysical judgments are based on absolute judgments (Engen \& Pfaffman, 1959, 1960; Garner, 1953; Garner \& Hake, 1951; Pollack, $1952,1953)$, and have shown that there exists an upper limit on the amount of information transferred by such judgments when the stimuli presented to subjects are unidimensional (Garner, 1962; Garner \& Hake, 1951; Pollack, 1952, 1953). This limit is usually called channel capacity and shows how much of the information contained in the physical stimuli is transferred by subjective judgments in the form of the identification of these stimuli.

Channel capacities for different sensory continua usually lie between 2 and 3 bits of information, corresponding to a very limited number, between 3 and 8 , of objective or discriminal categories. Generally, this limit shows that stimuli presented for identification by absolute judgment can be perfectly discriminated when their number does not exceed channel capacity (Garner, 1962). Channel capacity is, accordingly, a restrictive factor in sensory discrimination (Miller, 1956), and represents an important indicator of the functioning of different sensory analyzers.

The nature of absolute judgments is nominal. Subjects are asked to identify each stimulus by some conventional response (usually a number or a name). Such responses do not reflect the intensity properties of the presented stimuli or the differences among them; thus, subjects are not expressing subjective evaluations or measurements of

Reprint requests should be directed to: Ante Fulgosi, Odsjek za psihologiju, Filozofski fakultet, 41000 Zagreb, Yugoslavia. the intensities or differences. In contrast, in comparative judgment procedures, including magnitude estimation, which are more typical and widely used in contemporary psychophysics, subjects are asked to compare the intensities (or other properties, e.g., pitch) of stimuli. Thus, they are asked to perform a kind of subjective measurement of physical stimuli or the sensations provoked by them (A. Fulgosi, 1977, 1984, 1987).

This difference motivates our interest in the informational characteristics of comparative judgments, since they need not be the same as, or even similar to, those of absolute judgments. Procedures for examining the informational properties of comparative judgments have been developed by A. Fulgosi (1977) and applied to judgments of visual area by A. Fulgosi, Lugomer, and $\mathrm{Lj}$. Fulgosi $(1980,1986)$. When subjects judged visual areas with input information of 4 bits, transmitted information was 2.3 bits for ratio estimation, 2.9 bits for category judgment, and 2.9 bits for magnitude estimation. In one study (A. Fulgosi et al., 1980) it was found that the amount of transmitted information in different sensory systems was about 3 bits, considerably less than the input information, suggesting a restriction in the form of channel capacity.

On the basis of the informational aspects of quantitative judgments, A. Fulgosi $(1984,1987)$ developed a new objective psychophysics in which sensory systems are characterized by their efficiency in extracting intensity information from physical processes. The basic measurement units in this psychophysics are objectively definedintensity bits and a corresponding number of intensity 
units. One intensity bit is the amount of information about the intensity properties of stimuli (or intensity differences between them) that corresponds to perfect discrimination of two intensity categories or units. Intensity units determined in such a way are also called objective intensity units to distinguish them from the subjective units (e.g., magnitude estimations) that subjects use in their judgments. The number of intensity bits and the corresponding number of objective intensity units (intensity categories) are determined from subjective quantitative judgments. In this way, in the new objective psychophysics we distinguish objective indicators of sensory performance (intensity bits and units) from the subjective indicators (subjective scales, units, ranges, and ratios) that are used in traditional subjective psychophysics. These subjective indicators are expressed in objective terms (amount of transmitted intensity information or number of objective intensity units).

In the present investigation, magnitude estimations of weight were selected for informational analysis. Several psychophysical investigations have found that subjects are able to "measure" these kinds of stimuli or sensations quite faithfully. The exponents of the psychophysical weight and pressure functions are 1.4 and 1.1 , respectively (Stevens, 1975). The relative differential limen for experienced weights, measured in classical psychophysics, is about 0.02 (Oberlin, 1936), showing good differential sensitivity. It seems plausible that the amount of information in magnitude estimations will correspond to the amount of information contained in physical weights.

Our investigation had four main goals: (1) to see if, in the magnitude estimation of weights, there exists an upper limit on the amount of transmitted information in the form of channel capacity; (2) to determine the informational characteristics of the magnitude estimations of weights obtained by two procedures-with a standard always available for reference and with the standard presented only once per session; (3) to find the number of intensity bits and intensity units that subjects use in their magnitude estimations of weights, and to distribute or partition subjective estimates and scales in such objective units; and (4) to compare the informational values of magnitude estimations with those of absolute judgments.

We report three experiments. In the first, subjects were asked to judge each presented stimulus by comparing it with a standard stimulus, which was always available for reference, and expressing the ratio of the weights by the ratio of two numbers; in the second, subjects were asked to give magnitude estimations of the same stimuli with the standard stimulus presented only once at the beginning of each session; in the third, subjects were asked to make absolute judgments of the stimuli.

\section{METHOD}

\section{Subjects}

Subjects volunteered and were assigned to one of the two experimental groups on a random basis. A third group was formed from 5 other student volunteers. For each group, $N=5$. All groups contained 3 females and 2 males.

\section{Stimuli}

Ten stimulus weights, cylinders of the same size and volume $(7.3 \mathrm{~cm}$ high and $3.9 \mathrm{~cm}$ in diameter) but differing in weight from 22 to $292 \mathrm{~g}$ in equal steps of $30 \mathrm{~g}$, were used. Stimuli were arithmetically spaced in steps much larger than the respective differential limens. The last step of $30 \mathrm{~g}$, for example, is more than five times greater than the corresponding differential limen. The informational value of the stimulus set in each experiment was 3.32 bits.

\section{Procedure}

Each experiment was divided into 10 sessions. Two sessions were run on each of 5 consecutive days. In each session, each stimulus was presented in random order eight times. In this way, there were 80 presentations in each session. Only the responses from the second half of each experiment were analyzed, the first half of each experiment being treated as a training period.

In the experiment with absolute judgment, the subject was presented with each stimulus alone and asked to identify it with the proper number, from 1 , for the lightest, to 10 , for the heaviest. Before each experimental session, the subject was blindfolded. The experimenter placed the stimuli on the subject's dominant hand, in order from the lightest to the heaviest, and gave the identification number for each. The subject was asked to keep her/his elbow on the table and to move only the forearm and hand. During the first five sessions (the first half) of the experiment, the subjects were given feedback after each judgment (the experimenter gave the correct identification number for the stimulus just presented and judged). In the last five sessions (the second half) of the experiment no feedback was given.

The procedure in the first experiment with magnitude estimation was identical, except that (1) there was no feedback, and (2) the subject was asked to compare each presented stimulus with the standard stimulus, which was placed in her/his hand whenever requested. The standard was the stimulus of $52 \mathrm{~g}$ and its weight was designated as 10 . The subject's task was to express the ratio of the two weights by assigning a number: If the comparison stimulus seemed double the weight of the standard, it should be designated as 20; if it seemed three times as heavy, it should be designated as 30 ; and so on.

The procedure in the second magnitude estimation experiment was similar, except that the subject could not refer to the standard stimulus, which was $22 \mathrm{~g}$ rather than $52 \mathrm{~g}$. The standard was presented only once before each experimental session; the experimenter placed it in the subject's hand and said that its magnitude was 10. The subjects were asked to express the magnitudes of other weights as multiples or fractions of this modulus.

\section{RESULTS}

Following the procedure described by A. Fulgosi and Bartolović (1971), informational analyses were performed on individual data. For each subject, a stimulus $\times$ response matrix containing $\mathbf{4 0}$ estimations or identifications of each stimulus was formed, and from this matrix the following informational measures were determined: (1) average response uncertainty,

$$
H(y)=\sum_{y} p(y) \log p(y),
$$

where $p(y)$ is the probability of a particular magnitude estimation, defined as the ratio of the number of times 
Table 1

Average Response Uncertainty $[H(y)]$, Conditional Uncertainty $\left[H_{y}(y)\right]$, Transmitted Information $(T)$, and Number of Intensity/Discriminal Categories (No. Cat.) (Median and Range for 5 Subjects in Each of Three Experiments)

\begin{tabular}{llcccc}
\hline Experiment & Statistic & $H(y)$ & $H_{x}(y)$ & $T$ & No. Cat. \\
\hline Mag Est* & Median & 3.75 & 1.59 & 1.74 & 3.4 \\
& Range & $3.03-4.15$ & $1.29-2.29$ & $1.60-2.26$ & $3.1-4.8$ \\
Mag Est $\dagger$ & Median & 3.53 & 1.80 & 1.83 & 3.6 \\
& Range & $3.25-4.92$ & $1.34-3.10$ & $1.61-1.96$ & $3.1-3.9$ \\
Absolute Judgment & Median & & & 1.91 & 3.8 \\
& Range & & & $1.62-2.08$ & $3.1-4.2$ \\
\hline
\end{tabular}

*Magnitude estimation, standard always available for reference. †Magnitude estimation, standard presented once at beginning of each session.

it occurs to the total number (400) of magnitude estimations; (2) conditional uncertainty (response equivocation),

$$
H_{x}(y)=\sum_{x} p(x) \sum_{y} p_{x}(y) \log p_{x}(y),
$$

where $p(x)$ is the probability or proportion of a given stimulus $(0.10)$ from the stimulus set and $p_{x}(y)$ is the probability or proportion of a particular response (magnitude estimation) for stimulus $x$; (3) amount of transmitted information, $T$, as the difference between $H(y)$ and $H_{x}(y)$. (Usual formulas for average response uncertainty could also be used; see, e.g., Attneave, 1959, or Garner, 1962).

This method of analysis makes it possible to obtain informational indices for each subject in spite of the differences in numbers used for estimates or other kinds of judgments (A. Fulgosi, 1977). Table 1 summarizes these indices for the present study.

Neither for average response uncertainty, $H(x)$, nor for conditional uncertainty, $H_{x}(y)$, is there a reliable difference ( $p>.4$ by Mann-Whitney $U$ tests) between the two magnitude estimation experiments. For transmitted information, $T$, no pair of results from the two magnitude estimation experiments and the absolute judgment experiment differs reliably $(p>.2$ by Mann-Whitney $U$ tests). ${ }^{1}$

The rank order correlation tho between average response uncertainty and conditional uncertainty is +.91 and is significant $(p<.01)$. Rho between values of average response uncertainty and transmitted intensity information is a nonsignificant -.02 . Both coefficients were calculated from pooled results of the two magnitude estimation experiments.

The number of objective intensity categories or units corresponding to number of bits of transmitted information is given for each subject in magnitude estimation experiments by the antilogarithm of $T$. In the same way, the number of discriminal categories in the absolute judgment experiment was determined. No pair of $T$ values from the three experiments differs reliably $(p>.2$ by Mann-Whitney $U$ tests).

Subjective magnitude estimates were partitioned into objective intensity bits by dividing the total range of subjective units (the largest minus the smallest magnitude estimation) and the total ratio of subjective units (the largest divided by the smallest magnitude estimation) by the number of corresponding intensity bits for each subject. These values are shown in Table 2.

The differences between the two groups in range and in number of subjective units per bit are both reliable ( $p<.03$ by Mann-Whitney $U$ tests). Rhos between range of subjective estimates and transmitted information, -.50 , and between number of subjective units per bit and transmitted information, -.50 , are not significant.

Differences between the two groups in total ratio and ratio divided by number of bits are not significant $(p>.16)$. Rhos between ratio and $T,-.39$, and ratio/bit and $T,-.39$, are not significant.

Finally, informational values of 1 subjective unit were determined by dividing bits of transmitted information by the number of such units for each subject; these are also shown in Table 2. Differences in the informational values between the two groups are significant $(p=.03)$. Informational values of subjective units in the second magnitude estimation experiment are significantly smaller.

By dividing individual ranges and ratios of subjective units (estimates) by the number of objective intensity units,

Table 2

Range of Subjective Units (Largest Minus Smallest Magnitude Estimation), Ratio of Subjective Units, Range of Subjective

Units Used for Transmitting 1 Intensity Bit of Information, Part of the Subjective Ratio Used for Transmitting 1 Intensity Bit and Informational Value of 1 Subjective Unit for Two Magnitude Estimation Experiments

\begin{tabular}{|c|c|c|c|c|c|}
\hline Subject & Range & $\begin{array}{l}\text { Range } \\
\text { per Bit }\end{array}$ & Ratio & $\begin{array}{c}\text { Ratio } \\
\text { per Bit }\end{array}$ & $\begin{array}{c}\text { Bits } \\
\text { per Unit }\end{array}$ \\
\hline \multicolumn{6}{|c|}{ Standard Available } \\
\hline $\begin{array}{l}\text { A } \\
\text { B } \\
\text { C } \\
\text { D } \\
\text { E }\end{array}$ & $\begin{array}{r}46 \\
119 \\
59 \\
99 \\
199\end{array}$ & $\begin{array}{r}20.4 \\
74.2 \\
33.9 \\
49.4 \\
116.4\end{array}$ & $\begin{array}{r}12.5 \\
75.0 \\
60.0 \\
100.0 \\
200.0\end{array}$ & $\begin{array}{r}5.5 \\
46.9 \\
34.0 \\
50.0 \\
117.0\end{array}$ & $\begin{array}{l}.049 \\
.013 \\
.029 \\
.020 \\
.009\end{array}$ \\
\hline $\begin{array}{l}\text { Median } \\
\text { Mean }\end{array}$ & $\begin{array}{c}99 \\
104.4\end{array}$ & $\begin{array}{l}49.4 \\
58.9\end{array}$ & $\begin{array}{l}75.0 \\
89.5\end{array}$ & $\begin{array}{l}46.9 \\
50.8\end{array}$ & $\begin{array}{l}.020 \\
.018\end{array}$ \\
\hline \multicolumn{6}{|c|}{ Standard Presented Once } \\
\hline $\begin{array}{l}\mathbf{F} \\
\mathbf{G} \\
\mathbf{H} \\
\mathbf{I} \\
\mathbf{J}\end{array}$ & $\begin{array}{l}190 \\
340 \\
690 \\
445 \\
140\end{array}$ & $\begin{array}{r}96.9 \\
197.2 \\
429.1 \\
243.6 \\
76.2\end{array}$ & $\begin{array}{l}20.0 \\
35.0 \\
45.4 \\
90.0 \\
15.0\end{array}$ & $\begin{array}{r}10.2 \\
20.4 \\
28.2 \\
49.2 \\
8.2\end{array}$ & $\begin{array}{l}.010 \\
.005 \\
.002 \\
.004 \\
.013\end{array}$ \\
\hline $\begin{array}{l}\text { Median } \\
\text { Mean }\end{array}$ & $\begin{array}{l}340 \\
361\end{array}$ & $\begin{array}{l}243.6 \\
208.6\end{array}$ & $\begin{array}{l}35.0 \\
41.1\end{array}$ & $\begin{array}{l}20.4 \\
23.2\end{array}$ & $\begin{array}{l}.005 \\
.007\end{array}$ \\
\hline
\end{tabular}


one can obtain the number of subjective units and the part of the total ratio of magnitude estimations that corresponds to one objective intensity unit in the two magnitude estimation experiments. In magnitude estimation with a standard always available, subjects used a median number of 25 subjective units and, in magnitude estimation with a single presentation of the standard, 103 subjective units for each objective unit. Differences between the number of subjective units per objective unit in the two experiments is significant $(p=.03)$. Median values of parts of the total ratio corresponding to one objective intensity unit in the two magnitude estimation experiments are 24.2 with standard available and 10.6 with single presentation of standard. Differences between the ratios per objective intensity unit in the two experiments are not significant ( $p=.4$ by a Mann-Whitney $U$ test). Rho between the amount of transmitted intensity information and the number of subjective units for one objective unit is -.50 , not significant. Rho between the size of the ratio for one objective intensity unit and the amount of transmitted intensity information is -.41 , not significant. Both correlation coefficients were calculated by pooling the results over the two experiments.

\section{DISCUSSION}

Transmitted information in both magnitude estimation experiments is far below the intensity information in the set of stimuli judged. In two magnitude estimation experiments, a large part of the intensity information contained in the stimuli was lost. Subjects operate with only a few objective intensity categories or units in judging the magnitudes of variable stimuli by themselves or in judging differences between the standard and variable stimuli. Stimulus $\times$ response matrices of individual subjects in both magnitude estimation experiments show considerable overlapping of distributions of magnitude estimations for single stimuli. Subjects' ability to discriminate intensities of variable stimuli, or differences between the standard stimulus and variable stimuli, is poor even after a long period of practice. Thus, it seems justifiable to speak about a channel capacity in the magnitude estimation of weights.

These results agree with our earlier results, in which different types of physical stimuli were judged in different comparative judgmental procedures and analyzed in terms of information theory (A. Fulgosi et al., 1980, 1986). Those analyses showed that, despite the different procedures and stimuli, the amount of transmitted information in subjective measurement is restricted to less than 3 bits.

The projections of the physical continuum of weights in these experiments on the psychological continuum of experienced weights through magnitude estimation is far from perfect, even when the number of points on the physical continuum is small. We interpret this as showing that intensity sensations of the physical weights (and other kinds of stimuli as well) are varia! $! c$, precluding one-to- one mappings of the points of the physical and psychological dimensions.

In support of such an interpretation of the low values of information transmitted in magnitude estimations is the fact that subjects systematically give (with a few exceptions) several different estimates for each stimulus. They also use ranges and ratios of estimates that are much larger than those between the actual stimuli. This leads to amounts of response uncertainty (see Table 1) in magnitude experiments that are greater than the uncertainty or information in the stimulus set. But, by increasing response uncertainty, the subjects are, at the same time, increasing conditional uncertainty or response equivocation, so that channel capacity and amount of transmitted information are less than the information in the stimuli. The absence of correlation between response uncertainty and transmitted information (rho is -.02 , not significant) documents this connection between response uncertainty and response equivocation, for which rho is +.91 . The increased amount of response uncertainty seems to be a consequence and indicator of the instability of the sensory or subjective dimension on which physical stimuli are projected.

The data in Table 2 show that there are large differences between subjects when subjective scales are partitioned into objective intensity bits and objective intensity units. Subjects behave differently in judging the same weights and using numbers for their estimates. The range of subjective units is much larger in the situation with a single presentation of the standard than in that with a standard always available.

$U$ tests show that the differences between (1) the range of the subjective scales, (2) the range of subjective units needed to achieve 1 intensity bit, (3) number of subjective units for one objective intensity unit, and (4) informational values of subjective units in the two magnitude estimation experiments are significant. But, despite all differences in range, ratio, and number of subjective units, subjects are transmitting the same amount of information about the intensities of the stimuli. This indicates again that subjective estimates of objective intensities are informationally restricted and contain the same amount of intensity information in spite of the large apparent differences between such estimates.

The rank order correlation coefficients between the sizes of the subjective scales, expressed both as ranges and ratios, and transmitted information are negative but, due perhaps to the small number of subjects, not reliable. This, together with the nonsignificant correlation between the number of estimates and amount of transmitted information for each subject (which is -.11), indicates again that more number values and larger number ranges and ratios do not automatically imply greater amounts of transmitted information.

This evidence shows that subjective estimates, units, and scales do not reflect faithfully the intensities of stimuli; nevertheless, these estimates do contain intensity information that subjects were able to extract from the stimuli. 
Therefore, subjective estimates can be used in the new objective psychophysics as indicators of the efficiency and rate at which the sensory system is extracting information from the physical processes impinging on it (A. Fulgosi, 1984, 1987).

Comparison of the information values of absolute judgments and magnitude estimations discloses a high degree of similarity despite large apparent differences between these two kinds of judgments. It seems that the information-extraction ability of a sensory system is the limiting factor, always restricting the informational values of judgments to the same level.

\section{REFERENCES}

Attneave, F. (1959). Application of information theory to psychology. New York: Holt, Rinehart, \& Winston.

Engen, T., Praffman, C. (1959). Aboslute judgments of odor intensity. Journal of Experimental Psychology, 58, 23-26.

Engen, T., \& Paffman, C. (1960). Absolute judgments of odor quality. Journal of Experimental Psychology, 59, 214-219.

Fulgosi, A. (1977). Teorija informacije u psihofizici (Zbornik "Stručni skup psihologa DRB 1976' '; pp. 87-96). Zagreb: Drušvo psihologa Hrvatske.

FulGoSI, A. (1984). Informacijska psihofizika-nova objektivna psihofizika: $\boldsymbol{V}$ (Dani psihologije u Zadru, 1983; pp. 11-23). Zandar: Filozofski fakultet.

Fulgosi, A. (1987). Design of a new objective psychophysics. Manuscript submitted for publication.

Fulgosi, A., Bartolović, B. (1971). Practice and some methodological problems in unidimensional information transmission. Perception \& Psychophysics, 10, 283-285.

Fulgosi, A., Lugomer, G., \& Fulgosi, L. (1980). Informational characteristics of comparative judgments. Paper presented at the XXII International Congress of Psychology, Leipzig. (Abstracts p. 118)
Fulgosi, A., Lugomer, G., \& Fulgosi, LJ. (1986). An informational analysis of comparative judgments of visual areas. Bulletin of the Psychonomic Society, 24, 379-380.

GARNER, W. R. (1953). An informational analysis of absolute judgments of loudness. Joumal of Experimental Psychology, 46, 373-380.

GARNER, W. R. (1962). Uncertainty and structure as psychological concepts. New York: Wiley.

GARNER, W. R., HAKE, H. W. (1951). The amount of information in absolute judgments. Psychological Review, 58, 446-459.

Miller, G. A. (1956). The magical number seven, plus or minus two. Psychological Review, 63, 81-97.

OBERLIN, K. W. (1936). Variation in intensive sensitivity to lifted weights. Journal of Experimental Psychology, 19, 438-455.

PollaCK, I. (1952). The information of elementary auditory displays. Joumal of the Acoustical Society of America, 24, 745-749.

Pollack, I. (1953). The information of elementary auditory displays II. Journal of the Acoustical Society of America, 25, 765-769.

Stevens, S. S. (1975). Psychophysics: Introduction to its perceptual, neural and social prospects. New York: Wiley.

\section{NOTE}

1. Since different subjects in the two magnitude estimation experiments used from 11 to 41 estimates for 10 stimuli, transmission values were computed from stimulus $x$ response matrices of different sizes. For this reason, obtained transmission values may be corrected by the Miller-Madow formula, $(r-1)(k-1) \log _{2} e / 2 N$, where $r$ is number of rows (estimates) and $k$ is number of columns (stimuli). Median corrected transmission values are $1.53,1.48$, and 1.77 for magnitude estimation with standard available and not available and for absolute judgment, respectively. Mann-Whitney's $U$ test shows the differences between results for each pair of experiments to be insignificant with corrected transmission values, just as they were with uncorrected values.

(Manuscript received May 5, 1986; revision accepted for publication March 23, 1987.) 